\title{
The first-generation ABSORB BVS: awaiting dissolving outcomes
}

\author{
J. Elias $^{1}$ I. M. van Dongen ${ }^{1}$ J. P. S. Henriques ${ }^{1}$
}

Published online: 14 September 2017

(c) The Author(s) 2017. This article is an open access publication.

We thank Dr Shah for his response to our meta-analysis. As Dr Shah points out, in our meta-analysis the ABSORB II trial was the only study that reported 3-year follow-up. All the other trials had a follow-up duration of 2 years or less, and the AIDA trial reported a median follow-up of 2 years [1]. Therefore, the very-long-term clinical efficacy and safety of the bioresorbable vascular scaffold (BVS) are currently unknown.

Although the low numbers of events between 2-3 years of follow-up in both the ABSORB-Japan and ABSORBChina trials might be reassuring $[2,3]$, in the ABSORB II trial there were four scaffold thromboses in the Absorb BVS arm $(n=313)$ between $2-3$ year follow-up (rate of $\sim 1.2 \%$ ) [4]. Furthermore, several limitations of the ABSORB-Japan and ABSORB-China trials must be pointed out. Both trials only included about $15 \%(n=875)$ of the patients analysed in our meta-analysis, resulting in a weight of less than $5 \%$. Furthermore both trials included highly selected patients and lesions and the results are therefore not applicable to daily clinical practice.

Also, in the ABSORB-Japan trial almost $42 \%$ of the BVS patients were still on dual antiplatelet therapy (DAPT) at 3-year follow-up. In addition, no statement was given on the reasons for DAPT prolongation and whether patients who discontinued DAPT had an increased risk for stent thrombosis. In the ABSORB-China trial about $20 \%$ of pa-

Reply to the letter from R. Shah: 'Very-long-term efficacy of bioresorbable vascular scaffolds'. https://doi.org/10.1007/s12471017-1041-9.

J. Elias

j.p.henriques@amc.uva.nl tients were still on DAPT at 3-year follow-up. Although it is currently unknown if prolongation of DAPT will be able to prevent (late) scaffold thrombosis, variance in DAPT duration limits the results of the trials.

Nonetheless, even if the device thrombosis rate of the Absorb BVS is low between 2-3 years of follow-up, the cumulative device thrombosis rate for the Absorb BVS remains high compared with the Xience metallic stent, and any potential benefit is still unnoticed. A decline in scaffold thrombosis is probably something to be expected, since less of the scaffold is present during follow-up leading to fewer events. However, the real questions are what will happen in the following years after the scaffold is completely dissolved and whether the benefits will outbalance the (early) risks.

We agree with the author that further (longer and more) follow-up should be awaited to fully assess the possible benefit of the dissolving BVS. However, the reduction in scaffold thrombosis rate between 2-3 year follow-up is at best encouraging to further extend technical improvement and provide newer insights to improve outcomes. Still, until more long-term data are presented, with current knowledge the use of the Absorb BVS should be restricted to regulated clinical studies, if to be used at all.

Conflict of interest J. Elias, I.M. van Dongen and J.P.S. Henriques declare that they have no competing interests.

Open Access This article is distributed under the terms of the Creative Commons Attribution 4.0 International License (http:// creativecommons.org/licenses/by/4.0/), which permits unrestricted use, distribution, and reproduction in any medium, provided you give appropriate credit to the original author(s) and the source, provide a link to the Creative Commons license, and indicate if changes were made.

1 Academic Medical Center, University of Amsterdam, Amsterdam, The Netherlands 


\section{References}

1. Elias J, van Dongen IM, Kraak RP, et al. Mid-term and long-term safety and efficacy of bioresorbable vascular scaffolds versus metallic everolimus-eluting stents in coronary artery disease: a weighted meta-analysis of seven randomised controlled trials including 5577 patients. Neth Heart J. 2017;25:429-38.

2. Gao R. Randomized comparison of everolimus-eluting bioresorbable vascular Scaffolds vs. everolimus-eluting metallic stents in patients with coronary artery disease: 3-year clinical outcomes from ABSORB China. Presented at: annual EuroPCR conference; May 17, 2017; Paris, France. 2017. https://www.tctmd.com/slide/ randomized-comparison everolimus- eluting-bioresorbable-vascular-scaffolds-vs-everolimus. Accessed 10 Aug 2017.
3. Kozuma K. ABSORB Japan: 3-year clinical and angiographic results of a randomized trial evaluating the absorb bioresorbable vascular scaffoldvs. metallic drug eluting stent in de novo native coronary artery lesions. Presented at: annual EuroPCR conference; May 17, 2017; Paris, France. 2017. https://www.tctmd.com/slide/ absorb-japan-results-3-yearclinical-and-angiographic-results. Accessed 10 Aug 2017.

4. Serruys PW, Chevalier B, Sotomi Y, et al. Comparison of an everolimus-eluting bioresorbable scaffold with an everolimuseluting metallic stent for the treatment of coronary artery stenosis (ABSORB II): a 3 year, randomised, controlled, single-blind, multicentre clinical trial. Lancet. 2016;388:2479-91. 


\title{
Advertisement placed here.
}

\author{
SCS bohn \\ stafleu \\ CL van loghum \\ Springer Media
}

Houten 2017 